\title{
Monotone Iterative Technique and Symmetric Positive Solutions to Fourth-Order Boundary Value Problem with Integral Boundary Conditions
}

\author{
Huihui Pang and Chen Cai \\ College of Science, China Agricultural University, Beijing 100083, China \\ Correspondence should be addressed to Huihui Pang; phh2000@163.com
}

Received 9 April 2014; Accepted 6 June 2014; Published 18 August 2014

Academic Editor: Gabriele Bonanno

Copyright (c) $2014 \mathrm{H}$. Pang and C. Cai. This is an open access article distributed under the Creative Commons Attribution License, which permits unrestricted use, distribution, and reproduction in any medium, provided the original work is properly cited.

The purpose of this paper is to investigate the existence of symmetric positive solutions for a class of fourth-order boundary value problem: $u^{(4)}(t)+\beta u^{\prime \prime}(t)=f\left(t, u(t), u^{\prime \prime}(t)\right), 0<t<1, u(0)=u(1)=\int_{0}^{1} p(s) u(s) d s, u^{\prime \prime}(0)=u^{\prime \prime}(1)=\int_{0}^{1} q(s) u^{\prime \prime}(s) d s$, where $p, q \in L^{1}[0,1], f \in C([0,1] \times[0, \infty) \times(-\infty, 0],[0, \infty))$. By using a monotone iterative technique, we prove that the above boundary value problem has symmetric positive solutions under certain conditions. In particular, these solutions are obtained via the iteration procedures.

\section{Introduction}

The deformation of an elastic beam in equilibrium state, whose two ends are simply supported, can be described by a fourth-order ordinary differential equation BVP (short for boundary value problem). At present, two-point situation of fourth-order BVP has been studied by many authors, generally using the nonlinear alternatives of Leray-Schauder, the fixed point index theory, and the method of upper and lower solutions, monotone iteration; see [1-6].

Recently, problems with integral boundary value conditions arise naturally in thermal conduction problems [7], semiconductor problems [8], and hydrodynamic problems [9]. Hence, the existence results of positive solutions to this kind of problems have received a great deal of attentions. We refer the readers to [10-15].

In [13], Ma studied the following problem:

$$
\begin{gathered}
u^{(4)}(t)=h(t) f(t, u), \quad 0<t<1, \\
u(0)=u(1)=\int_{0}^{1} p(s) u(s) d s, \\
u^{\prime \prime}(0)=u^{\prime \prime}(1)=\int_{0}^{1} q(s) u^{\prime \prime}(s) d s,
\end{gathered}
$$

where $p, q \in L^{1}[0,1]$ and $h$ and $f$ are continuous. The existence of at least one symmetric positive solution is obtained by the application of the fixed point index in cones.

In [14], authors study the existence and nonexistence of symmetric positive solutions of the following fourth-order BVP:

$$
\begin{aligned}
\left(\phi_{p}\left(x^{\prime \prime}(t)\right)\right)^{\prime \prime} & =w(t) f(t, x(t)), \quad 0<t<1, \\
x(0) & =x(1)=\int_{0}^{1} g(s) x(s) d s, \\
\phi_{p}\left(x^{\prime \prime}(0)\right) & =\phi_{p}\left(x^{\prime \prime}(1)\right)=\int_{0}^{1} h(s) \phi_{p}\left(x^{\prime \prime}(s)\right) d s .
\end{aligned}
$$

The argument was based on the fixed point theory in cones.

For fourth-order differential equation

$$
u^{(4)}(t)+\beta u^{\prime \prime}(t)=\lambda f\left(t, u(t), u^{\prime \prime}(t)\right), \quad 0<t<1,
$$

subject to boundary value conditions (2), author in [15] established the existence of positive solutions by the use of the Krasnoseliis fixed point theorem in cone.

The existing literature indicates that researches of fourthorder two point BVPs are excellent and methods are developed to be various. However, as to fourth-order BVPs with 
integral boundary value conditions, methods applied are relatively limited. Most of results are obtained by the use of fixed point theory in the cone or the fix point index theorem.

In this paper, we will apply the monotone iterative technique to the following fourth-order BVP with integral boundary conditions:

$$
\begin{aligned}
u^{(4)}(t)+\beta u^{\prime \prime}(t) & =f\left(t, u(t), u^{\prime \prime}(t)\right), \quad 0<t<1, \\
u(0) & =u(1)=\int_{0}^{1} p(s) u(s) d s, \\
u^{\prime \prime}(0) & =u^{\prime \prime}(1)=\int_{0}^{1} q(s) u^{\prime \prime}(s) d s .
\end{aligned}
$$

We do not assume that the upper and lower solutions to the boundary value problem should exist but construct the specific form of the symmetric upper and lower solutions. And we will construct successive iterative schemes for approximating solutions. In addition, it is worth stating that the first term of our iterative scheme is a simple function or a constant function. Therefore, the iterative scheme is feasible. Under the appropriate assumptions on nonlinear term, a new and general result to the existence of symmetric positive solution of BVP (5) and (6) is obtained.

We assume that the following conditions hold throughout the paper:

$\left(S_{1}\right) \pi^{2} / 4 \leqslant \beta<\pi^{2} ;$

$\left(S_{2}\right) \int_{0}^{1} p(s) d s<1, \int_{0}^{1} q(s) \sin \sqrt{\beta} s d s+\int_{0}^{1} q(s) \sin \sqrt{\beta}(1-$ s) $d s<\sin \sqrt{\beta}$;

$\left(S_{3}\right) f \in C([0,1] \times[0,+\infty) \times(-\infty, 0],[0,+\infty)), p, q \in$ $L^{1}[0,1], p(s) \geqslant 0, q(s) \geqslant 0$.

\section{Preliminaries}

Given $m(x) \in L^{1}[0,1]$, let

$$
\begin{aligned}
\delta_{1}= & 1-\int_{0}^{1} m(x) d x \\
\delta_{2}= & \sin \sqrt{\beta}-\int_{0}^{1} m(x) \sin \sqrt{\beta} x d x \\
& -\int_{0}^{1} m(x) \sin \sqrt{\beta}(1-x) d x
\end{aligned}
$$

and $\delta_{i} \neq 0, i=1,2$. Denoted by $H_{i}(t, s), i=1,2$, the Green's function of the following problem:

$$
\begin{aligned}
& -u^{\prime \prime}(t)+\lambda_{i} u(t)=0, \quad 0<t<1, \\
& u(0)=u(1)=\int_{0}^{1} m(s) u(s) d s .
\end{aligned}
$$

Then, careful calculation yields

$$
\begin{aligned}
& H_{1}(t, s) \\
& \quad=G_{1}(t, s)+\frac{1}{\delta_{1}} \int_{0}^{1} G_{1}(s, x) m(x) d x, \\
& G_{1}(t, s) \\
& \quad= \begin{cases}t(1-s), & 0 \leqslant t \leqslant s \leqslant 1, \\
s(1-t), & 0 \leqslant s \leqslant t \leqslant 1,\end{cases} \\
& H_{2}(t, s) \\
& \quad=G_{2}(t, s) \\
& \quad+\frac{\sin \sqrt{\beta} t+\sin \sqrt{\beta}(1-t)}{\delta_{2}} \int_{0}^{1} G_{2}(s, x) m(x) d x,
\end{aligned}
$$

$G_{2}(t, s)$

$$
= \begin{cases}\frac{\sin \sqrt{\beta} t \sin \sqrt{\beta}(1-s)}{\sqrt{\beta} \sin \sqrt{\beta}}, & 0 \leqslant t \leqslant s \leqslant 1, \\ \frac{\sin \sqrt{\beta} \sin \sqrt{\beta}(1-t)}{\sqrt{\beta} \sin \sqrt{\beta}}, & 0 \leqslant s \leqslant t \leqslant 1 .\end{cases}
$$

Denote

$$
\begin{aligned}
\rho_{1}= & \frac{1}{1-\int_{0}^{1} p(x) d x} ; \\
\rho_{2}= & \sin \sqrt{\beta}-\int_{0}^{1} q(x) \sin \sqrt{\beta} x d x \\
& -\int_{0}^{1} q(x) \sin \sqrt{\beta}(1-x) d x ; \\
\rho_{2}(t)= & \frac{1}{\rho_{2}}(\sin \sqrt{\beta} t+\sin \sqrt{\beta}(1-t)) .
\end{aligned}
$$

Lemma 1 (see [15]). Suppose that $\left(S_{1}\right)-\left(S_{3}\right)$ hold. Then, for any $g \in C[0,1], u$ solves the problem

$$
\begin{aligned}
& u^{(4)}(t)+\beta u^{\prime \prime}(t)=g(t), \quad 0<t<1, \\
& u(0)=u(1)=\int_{0}^{1} p(s) u(s) d s, \\
& u^{\prime \prime}(0)=u^{\prime \prime}(1)=\int_{0}^{1} q(s) u^{\prime \prime}(s) d s
\end{aligned}
$$

if and only if $u(t)=\int_{0}^{1} \int_{0}^{1} K_{1}(t, s) K_{2}(s, \tau) g(\tau) d \tau d s$, where

$$
\begin{aligned}
& K_{1}(t, s)=G_{1}(t, s)+\rho_{1} \int_{0}^{1} G_{1}(s, x) p(x) d x, \\
& K_{2}(s, \tau)=G_{2}(s, \tau)+\rho_{2}(s) \int_{0}^{1} G_{2}(\tau, x) q(x) d x .
\end{aligned}
$$
know

During the process of getting the above solution, we can also

$$
u^{\prime \prime}(t)=-\int_{0}^{1} K_{2}(t, s) g(s) d s .
$$


Lemma 2. If $\left(S_{2}\right)$ is satisfied, the following results are true:

(1) $K_{i}(t, s) \geqslant 0$, for $t, s \in[0,1], i=1,2$;

(2) $G_{i}(1-t, 1-s)=G_{i}(t, s), G_{i}(t, s) \leqslant G_{i}(t, t)$, for $t, s \in$ $[0,1], i=1,2$.

Denote

$$
\begin{aligned}
l_{1} & =\int_{0}^{1} G_{1}(x, x) p(x) d x ; \\
l_{2} & =\int_{0}^{1} G_{2}(x, x) q(x) d x ; \\
h(t) & =G_{2}(t, t)+\rho_{2}(t) l_{2} ; \\
l_{3} & =\int_{0}^{1} h(t) d t .
\end{aligned}
$$

As $\sqrt{\beta} \in[\pi / 2, \pi)$, it is easy to check that $h(t)=h(1-t)$ and $h^{\prime \prime}(t) \leqslant 0$, for $t \in[0,1]$. Hence, from the symmetry and concavity of $h(t)$, we have

$$
h(t) \leqslant h\left(\frac{1}{2}\right) \leqslant 2 \int_{0}^{1} h(t) d t=2 l_{3} .
$$

In addition, for $t, s \in[0,1]$, the following results hold:

$$
\begin{aligned}
K_{1}(t, s)= & G_{1}(t, s)+\rho_{1} \int_{0}^{1} G_{1}(s, x) p(x) d x \\
\leqslant & G_{1}(t, t)+\rho_{1} \int_{0}^{1} G_{1}(x, x) p(x) d x \\
= & t(1-t)+\rho_{1} l_{1}, \\
& K_{1}\left(\frac{1}{2}, s\right) \leqslant \frac{1}{4}+\rho_{1} l_{1} .
\end{aligned}
$$

Further,

$$
\begin{aligned}
K_{2}(s, \tau) & =G_{2}(s, \tau)+\rho_{2}(s) \int_{0}^{1} G_{2}(\tau, x) q(x) d x \\
& \leqslant G_{2}(s, s)+\rho_{2}(s) \int_{0}^{1} G_{2}(x, x) q(x) d x \\
& =G_{2}(s, s)+\rho_{2}(s) l_{2} \\
& =h(s)
\end{aligned}
$$

and therefore

$$
K_{2}\left(\frac{1}{2}, \tau\right) \leqslant h\left(\frac{1}{2}\right) .
$$

We consider Banach space $E=C^{2}[0,1]$ equipped with the norm $\|u\|=\max \left\{\|u\|_{\infty},\left\|u^{\prime \prime}\right\|_{\infty}\right\}$, where $\|u\|_{\infty}=$ $\sup _{t \in[0,1]}|u(t)|$. In this paper, a symmetric positive solution $u^{*}$ of (5) means a function which is symmetric and positive on $(0,1)$ and satisfies $(5)$ as well as the boundary conditions (6).

In this paper, we always suppose that the following assumptions hold:
$\left(\mathrm{H}_{1}\right) f(t, u, v)=f(1-t, u, v)$ for $t \in[0,1], u \in[0, \infty), v \in$ $(-\infty, 0]$

$\left(\mathrm{H}_{2}\right) f\left(t, u_{1}, v_{1}\right) \leqslant f\left(t, u_{2}, v_{2}\right)$, for $0 \leqslant u_{1} \leqslant u_{2}<+\infty, 0 \leqslant$ $\left|v_{1}\right| \leqslant\left|v_{2}\right|<+\infty$

$\left(\mathrm{H}_{3}\right) f(t, 0,0) \not \equiv 0$, for $t \in[0,1]$.

Denote

$$
\begin{array}{r}
P=\left\{u \in E: u(t) \geqslant 0, u^{\prime \prime}(t) \leqslant 0,\right. \\
u(t)=u(1-t), t \in[0,1]\} .
\end{array}
$$

It is easy to see that $P$ is a cone in $E$.

We define the operator $T$ as follows:

$$
\begin{array}{r}
(T u)(t)=\iint_{0}^{1} K_{1}(t, s) K_{2}(s, \tau) f\left(\tau, u(\tau), u^{\prime \prime}(\tau)\right) d \tau d s, \\
t \in[0,1] .
\end{array}
$$

By the above argument, we know that, for any $u \in E, T u \in E$ and

$$
\begin{array}{r}
(T u)^{\prime \prime}(t)=-\int_{0}^{1} K_{2}(t, \tau) f\left(\tau, u(\tau), u^{\prime \prime}(\tau)\right) d \tau, \\
t \in[0,1] .
\end{array}
$$

Lemma 3. If $\left(S_{1}\right)-\left(S_{3}\right)$ are satisfied, $T: P \rightarrow P$ is completely continuous; that is, $T$ is continuous and compact.

Proof. For any $u \in P$, from (21) and (22), combining Lemma 2 and $\left(S_{3}\right)$, we know that $(T u)(t) \geqslant 0$ and $(T u)^{\prime \prime}(t) \leqslant 0$ for $t \in[0,1]$. We now prove that $T u$ is symmetric about $1 / 2$.

For $t \in[0,1]$,

$$
\begin{gathered}
(\mathrm{Tu})(1-t) \\
=\iint_{0}^{1} K_{1}(1-t, s) K_{2}(s, \tau) \\
\cdot f\left(\tau, u(\tau), u^{\prime \prime}(\tau)\right) d \tau d s \\
=\iint_{1}^{0} G_{1}(1-t, 1-s) G_{2}(1-s, 1-\tau) \\
\cdot f\left(1-\tau, u(1-\tau), u^{\prime \prime}(1-\tau)\right) \\
\cdot d(1-\tau) d(1-s) \\
+\int_{1}^{0} \int_{0}^{1} G_{1}(1-t, 1-s) \\
\cdot\left(\rho_{2}(1-s) \int_{0}^{1} G_{2}(\tau, x) q(x) d x\right) \\
\cdot f\left(\tau, u(\tau), u^{\prime \prime}(\tau)\right) d \tau d(1-s)
\end{gathered}
$$




$$
\begin{gathered}
+\iint_{0}^{1}\left(\rho_{1} \int_{0}^{1} G_{1}(s, x) p(x) d x\right) \\
\cdot G_{2}(s, \tau) f\left(\tau, u(\tau), u^{\prime \prime}(\tau)\right) d \tau d s \\
+\iint_{0}^{1}\left(\rho_{1} \int_{0}^{1} G_{1}(s, x) p(x) d x\right) \\
=\iint_{0}^{1} G_{1}(t, s) G_{2}(s, \tau) \\
+f\left(\tau, u(\tau), u^{\prime \prime}(\tau)\right) d \tau d s \\
\left.+\iint_{0}^{1} G_{1}(t, s)\left(\rho_{2}(s) \int_{0}^{1} G_{2}(\tau, x) q(x) d x\right), u^{\prime \prime}(\tau)\right) d \tau d s \\
+\iint_{0}^{1}\left(\rho_{1} \int_{0}^{1} G_{1}(s, x) p(x) d x\right) \\
+\iint_{0}^{1}\left(G_{2}(s, \tau) f\left(\tau, u(\tau), u^{\prime \prime}(\tau)\right) d \tau d s\right. \\
\left.\quad \cdot g_{0}^{1} G_{1}(s, x) p(x) d x\right) \\
+ \\
+G_{2}(s, \tau) f\left(\tau, u(\tau), u^{\prime \prime}(\tau)\right) d \tau d s
\end{gathered}
$$

So, $T P \subset P$. The continuity of $T$ is obvious. We now prove that $T$ is compact. Let $\Omega \subset P$ be a bounded set. Then, there exists $R$ such that

$$
\Omega=\{u \in P:\|u\| \leqslant R\} .
$$

For any $u \in \Omega$, we have

$$
\begin{aligned}
& 0 \leqslant f\left(t, u(t), u^{\prime \prime}(t)\right) \\
& \leqslant \max \left\{f\left(t, u, u^{\prime \prime}\right) \mid t \in[0,1],\right. \\
& \left.\quad u \in[0, R], u^{\prime \prime} \in[-R, 0]\right\} \\
& =: M .
\end{aligned}
$$

Therefore, from (17) and (18), we have

$$
\begin{aligned}
\|T u\|_{\infty}= & (T u)\left(\frac{1}{2}\right) \\
= & \iint_{0}^{1} K_{1}\left(\frac{1}{2}, s\right) K_{2}(s, \tau) \\
& \cdot f\left(\tau, u(\tau), u^{\prime \prime}(\tau)\right) d \tau d s
\end{aligned}
$$

$$
\begin{aligned}
& \leqslant M \iint_{0}^{1}\left(\frac{1}{4}+\rho_{1} l_{1}\right) h(s) d \tau d s \\
& =\left(\frac{1}{4}+\rho_{1} l_{1}\right) l_{3} M
\end{aligned}
$$

and from (19), we have

$$
\begin{aligned}
\left\|(T u)^{\prime \prime}\right\|_{\infty} & =-(T u)^{\prime \prime}\left(\frac{1}{2}\right) \\
& =\int_{0}^{1} K_{2}\left(\frac{1}{2}, \tau\right) f\left(\tau, u(\tau), u^{\prime \prime}(\tau)\right) d \tau \\
& \leqslant M \int_{0}^{1} h\left(\frac{1}{2}\right) d \tau \\
& =M h\left(\frac{1}{2}\right) .
\end{aligned}
$$

So, $\|T u\|$ is uniformly bounded. Next we prove that $T u$ is equicontinuous.

For $0 \leqslant t_{1} \leqslant t_{2} \leqslant s \leqslant 1$, we have

$$
\begin{aligned}
& \left\|(T u)\left(t_{2}\right)-(T u)\left(t_{1}\right)\right\|_{\infty} \\
& =\iint_{0}^{1}\left|K_{1}\left(t_{2}, s\right)-K_{1}\left(t_{1}, s\right)\right| \\
& \cdot K_{2}(s, \tau) f\left(\tau, u(\tau), u^{\prime \prime}(\tau)\right) d \tau d s \\
& \leqslant M \iint_{0}^{1}\left|K_{1}\left(t_{2}, s\right)-K_{1}\left(t_{1}, s\right)\right| \\
& \quad \cdot K_{2}(s, \tau) d \tau d s \\
& =M \iint_{0}^{1}\left|G_{1}\left(t_{2}, s\right)-G_{1}\left(t_{1}, s\right)\right| \\
& \quad \cdot K_{2}(s, \tau) d \tau d s \\
& \leqslant M \iint_{0}^{1}\left|t_{2}-t_{1}\right| K_{2}(s, \tau) d \tau d s \\
& =N_{1}\left|t_{2}-t_{1}\right|,
\end{aligned}
$$

where $N_{1}=M \iint_{0}^{1} K_{2}(s, \tau) d \tau d s$ and

$$
\begin{aligned}
& \left\|(T u)^{\prime \prime}\left(t_{2}\right)-(T u)^{\prime \prime}\left(t_{1}\right)\right\|_{\infty} \\
& \leqslant M \int_{0}^{1}\left|K_{2}\left(t_{2}, \tau\right)-K_{2}\left(t_{1}, \tau\right)\right| d \tau \\
& \leqslant M \int_{0}^{1}\left|G_{2}\left(t_{2}, \tau\right)-G_{2}\left(t_{1}, \tau\right)\right| d \tau \\
& +M\left|\rho_{2}\left(t_{2}\right)-\rho_{2}\left(t_{1}\right)\right| \\
& \quad \cdot \iint_{0}^{1} G_{2}(\tau, x) q(x) d x d \tau
\end{aligned}
$$


According to the Lagrange mean value theorem, we obtain that

$$
\begin{aligned}
& \left|G_{2}\left(t_{2}, \tau\right)-G_{2}\left(t_{1}, \tau\right)\right| \\
& \quad=\frac{\sin \sqrt{\beta}(1-\tau)}{\sqrt{\beta} \sin \sqrt{\beta}}\left|\sin \sqrt{\beta} t_{2}-\sin \sqrt{\beta} t_{1}\right| \\
& \quad \leqslant \frac{1}{\sqrt{\beta} \sin \sqrt{\beta}}\left|\sqrt{\beta} t_{2}-\sqrt{\beta} t_{1}\right| \\
& \quad=\frac{1}{\sin \sqrt{\beta}}\left|t_{2}-t_{1}\right| .
\end{aligned}
$$

Similarly, we have

$$
\left|\rho_{2}\left(t_{2}\right)-\rho_{2}\left(t_{1}\right)\right| \leqslant \frac{2 \sqrt{\beta}}{\rho_{2}}\left|t_{2}-t_{1}\right| .
$$

Hence, there exists a positive constant $N_{2}$ such that

$$
\left\|(T u)^{\prime \prime}\left(t_{2}\right)-(T u)^{\prime \prime}\left(t_{1}\right)\right\|_{\infty} \leqslant N_{2}\left|t_{2}-t_{1}\right| .
$$

And the similar results can be obtained for $0 \leqslant s \leqslant t_{1} \leqslant t_{2} \leqslant 1$ and $0 \leqslant t_{1} \leqslant s \leqslant t_{2} \leqslant 1$.

The Arzelà-Ascoli theorem guarantees that $T \Omega$ is relatively compact which means that $T$ is compact.

\section{Existence and Iterative of Solutions for BVP (5) and (6)}

Theorem 4. Assume that $\left(H_{1}\right)-\left(H_{3}\right)$ hold. If there exists two positive numbers $a_{1}<$ a such that

$$
\sup _{t \in[0,1]} f(t, a, a) \leqslant a_{1}
$$

where $a$ and $a_{1}$ satisfy

$$
a \geqslant \max \left\{\left(\frac{1}{4}+\rho_{1} l_{1}\right) l_{3}, 2 l_{3}, h\left(\frac{1}{2}\right)\right\} a_{1} .
$$

Then, problem (5) and (6) has concave symmetric positive solution $w^{*}, v^{*} \in P$ with

$$
\begin{gathered}
\left\|w^{*}\right\|_{\infty} \leqslant a, \\
\lim _{n \rightarrow \infty} T^{n} w_{0}=w^{*},
\end{gathered}
$$

where

$$
\begin{gathered}
w_{0}(t)=a_{1} l_{3}\left(t(1-t)+\rho_{1} l_{1}\right), \\
\left\|v^{*}\right\|_{\infty} \leqslant a, \\
\lim _{n \rightarrow \infty} T^{n} v_{0}=v^{*},
\end{gathered}
$$

where

$$
v_{0}(t)=0
$$

Proof. We denote $P_{a}=\{w \in P:\|w\| \leqslant a\}$. In what follows, we first prove that $T P_{a} \subset P_{a}$.

Let $w \in P_{a}$; then $0 \leqslant w(t) \leqslant \sup _{t \in[0,1]} w(t)=\|w\|_{\infty} \leqslant a$, $\left|w^{\prime \prime}(t)\right| \leqslant \sup _{t \in[0,1]}\left|w^{\prime \prime}(t)\right|=\left\|w^{\prime \prime}\right\|_{\infty} \leqslant a$.

By assumption $\left(\mathrm{H}_{2}\right)$ and (33), for $t \in[0,1]$, we have

$$
0 \leqslant f\left(t, w(t), w^{\prime \prime}(t)\right) \leqslant a_{1}
$$

For any $w(t) \in P_{a}$, by Lemma 3 , we know that $T w \in P$. According to (17), (18), and (33), we get

$$
\begin{aligned}
\|T w\|_{\infty}= & (T w)\left(\frac{1}{2}\right) \\
= & \iint_{0}^{1} K_{1}\left(\frac{1}{2}, s\right) K_{2}(s, \tau) \\
& \cdot f\left(\tau, u(\tau), u^{\prime \prime}(\tau)\right) d \tau d s \\
\leqslant & a_{1} \iint_{0}^{1}\left(\frac{1}{4}+\rho_{1} l_{1}\right) h(s) d \tau d s \\
= & a_{1}\left(\frac{1}{4}+\rho_{1} l_{1}\right) \int_{0}^{1} h(s) d s \\
= & a_{1} l_{3}\left(\frac{1}{4}+\rho_{1} l_{1}\right) \leqslant a,
\end{aligned}
$$

and from (19) and (33), we get

$$
\begin{aligned}
\left\|(T w)^{\prime \prime}\right\|_{\infty} & =-(T w)^{\prime \prime}\left(\frac{1}{2}\right) \\
& =\int_{0}^{1} K_{2}\left(\frac{1}{2}, \tau\right) f\left(\tau, u(\tau), u^{\prime \prime}(\tau)\right) d \tau \\
& \leqslant a_{1} \int_{0}^{1} K_{2}\left(\frac{1}{2}, \tau\right) d \tau \\
& \leqslant a_{1} \int_{0}^{1} h\left(\frac{1}{2}\right) d \tau \\
& =a_{1} h\left(\frac{1}{2}\right) \leqslant a .
\end{aligned}
$$

Hence, $\|T w\| \leqslant a$. Thus, we get $T P_{a} \subset P_{a}$. Let $w_{0}(t)=$ $a_{1} l_{3}\left(t(1-t)+\rho_{1} l_{1}\right)$, for $t \in[0,1]$; then $\left\|w_{0}\right\| \leqslant a$ and $w_{0}(t) \in P_{a}$. Let $w_{1}(t)=T w_{0}$; then $w_{1} \in P_{a}$. We denote

$$
w_{n+1}=T w_{n}=T^{n+1} w_{0} \quad(n=0,1,2, \ldots) .
$$

From the definition of $T$, (16), (18), and (38), it follows that

$$
\begin{aligned}
& w_{1}(t)=\left(T w_{0}\right)(t) \\
&=\iint_{0}^{1} K_{1}(t, s) K_{2}(s, \tau) \\
& \quad \cdot f\left(\tau, w_{0}(\tau), w_{0}^{\prime \prime}(\tau)\right) d \tau d s
\end{aligned}
$$




$$
\begin{aligned}
& \leqslant a_{1} \iint_{0}^{1} K_{1}(t, s) K_{2}(s, \tau) d \tau d s \\
& \leqslant a_{1} \iint_{0}^{1}\left(t(1-t)+\rho_{1} l_{1}\right) h(s) d \tau d s \\
& =a_{1}\left(t(1-t)+\rho_{1} l_{1}\right) \int_{0}^{1} h(s) d s \\
& =a_{1} l_{3}\left(t(1-t)+\rho_{1} l_{1}\right) \\
& =w_{0}(t) .
\end{aligned}
$$

On the other hand, from (15), (18), and (38), we have

$$
\begin{aligned}
\left|w_{1}^{\prime \prime}(t)\right| & =\left|\left(T w_{0}\right)^{\prime \prime}(t)\right| \\
& =\int_{0}^{1} K_{2}(t, \tau) f\left(\tau, w_{0}(\tau), w_{0}^{\prime \prime}(\tau)\right) d \tau \\
& \leqslant a_{1} \int_{0}^{1} K_{2}(t, \tau) d \tau \\
& \leqslant a_{1} \int_{0}^{1} h(t) d \tau \\
& =a_{1} h(t) \\
& \leqslant 2 a_{1} l_{3} \\
& =\left|w_{0}^{\prime \prime}(t)\right| .
\end{aligned}
$$

From $\left(\mathrm{H}_{2}\right)$, it follows that

$$
\begin{array}{r}
w_{2}(t)=\left(T w_{1}\right)(t) \leqslant\left(T w_{0}\right)(t)=w_{1}(t), \quad 0 \leqslant t \leqslant 1, \\
\left|w_{2}^{\prime \prime}(t)\right|=\left|\left(T w_{1}\right)^{\prime \prime}(t)\right| \leqslant\left|\left(T w_{0}\right)^{\prime \prime}(t)\right|=\left|w_{1}^{\prime \prime}(t)\right|, \\
0 \leqslant t \leqslant 1 .
\end{array}
$$

By induction,

$$
\begin{gathered}
w_{n+1}(t) \leqslant w_{n}(t), \\
\left|w_{n+1}^{\prime \prime}(t)\right| \leqslant\left|w_{n}^{\prime \prime}(t)\right|, \\
0 \leqslant t \leqslant 1 \quad(n=0,1,2, \ldots) .
\end{gathered}
$$

Since $T P_{a} \subset P_{a}$, we have $w_{n} \in P_{a}, n=0,1,2, \ldots$ From Lemma 3, $T$ is completely continuous. We assert that $\left\{w_{n}\right\}_{n=1}^{\infty}$ has a convergent subsequence $\left\{w_{n_{k}}\right\}_{k=1}^{\infty}$ and there exists $w^{*} \in$ $P_{a}$ such that $w_{n_{\mathrm{k}}} \rightarrow w^{*}$.

Let $v_{0}=0, t \in[0,1]$; then $v_{0} \in P_{a}$. Let $v_{1}=T v_{0}$; then $v_{1} \in P_{a}$; we denote

$$
v_{n+1}=T v_{n}=T^{n+1} v_{0}, \quad n=0,1,2, \ldots
$$

Similarly to $\left\{w_{n}\right\}_{n=1}^{\infty}$, we assert that $\left\{v_{n}\right\}_{n=1}^{\infty}$ has a convergent subsequence $\left\{v_{n_{k}}\right\}_{k=1}^{\infty}$ and there exists $v^{*} \in P_{a}$, such that $v_{n_{k}} \rightarrow v^{*}$.
Since $v_{1}(t)=\left(T v_{0}\right)(t)=(T 0)(t) \in P_{a}$, we have

$$
\begin{gathered}
v_{1}(t)=\left(T v_{0}\right)(t)=(T 0)(t) \geqslant 0, \quad 0 \leqslant t \leqslant 1, \\
\left|v_{1}^{\prime \prime}(t)\right|=\left|\left(T v_{0}\right)^{\prime \prime}(t)\right|=\left|(T 0)^{\prime \prime}(t)\right| \geqslant 0, \\
0 \leqslant t \leqslant 1 .
\end{gathered}
$$

Hence,

$$
\begin{array}{r}
v_{2}(t)=\left(T v_{1}\right)(t) \geqslant(T 0)(t)=v_{1}(t), \quad 0 \leqslant t \leqslant 1, \\
\left|v_{2}^{\prime \prime}(t)\right|=\left|\left(T v_{1}\right)^{\prime \prime}(t)\right| \geqslant\left|(T 0)^{\prime \prime}(t)\right|=\left|v_{1}^{\prime \prime}(t)\right|, \\
0 \leqslant t \leqslant 1 .
\end{array}
$$

By induction, $v_{n+1} \geqslant v_{n},\left|v^{\prime \prime}{ }_{n+1}(t)\right| \geqslant\left|v_{n}^{\prime \prime}(t)\right|, 0 \leqslant t \leqslant 1$, $(n=0,1,2, \ldots)$. Hence, we assert that $v_{n} \rightarrow v^{*}, T v^{*}=v^{*}$.

If $f(t, 0,0) \neq \equiv 0,0 \leqslant t \leqslant 1$, then the zero function is not the solution of BVP (5) and (6). Thus, $\max _{0 \leqslant t \leqslant 1}\left|v^{*}(t)\right|>0$; we have

$$
v^{*} \geqslant \min \{t, 1-t\} \max _{0 \leqslant t \leqslant 1}\left|v^{*}(t)\right|>0, \quad 0<t<1 .
$$

It is well known that the fixed point of operator $T$ is the solution of BVP (5) and (6). Therefore, $w^{*}$ and $v^{*}$ are two positive, concave, and symmetric solutions of BVP (5) and (6).

Example 5. Consider the following fourth-order boundary value problem with integral boundary conditions:

$$
\begin{aligned}
u^{(4)}(t)+\frac{\pi^{2}}{4} u^{\prime \prime}(t) & =f\left(t, u(t), u^{\prime \prime}(t)\right), \quad 0<t<1, \\
u(0) & =u(1)=\int_{0}^{1} s u(s) d s \\
u^{\prime \prime}(0) & =u^{\prime \prime}(1)=\int_{0}^{1} s u^{\prime \prime}(s) d s
\end{aligned}
$$

where

$$
f(t, u, v)=\frac{1}{30}\left(\sqrt{t(1-t)}+\frac{1}{2}\right)\left[v^{2}+\ln (u+2)\right] .
$$

The calculation yields

$$
\begin{aligned}
& \rho_{1}=2, \\
& \rho_{2}=\frac{\pi-2}{\pi}, \\
& l_{1}=\frac{1}{12}, \\
& l_{2}=\frac{1}{\pi^{2}}, \\
& l_{3}=\frac{2}{\pi(\pi-2)},
\end{aligned}
$$




$$
\begin{aligned}
\rho_{2}(t)= & \frac{\sin (\pi / 2) t+\sin (\pi / 2)(1-t)}{\rho_{2}}, \\
h(t)= & \frac{2}{\pi} \sin \frac{\pi}{2} t \sin \frac{\pi}{2}(1-t) \\
& +\frac{\sin (\pi / 2) t+\sin (\pi / 2)(1-t)}{\pi(\pi-2)}, \\
h\left(\frac{1}{2}\right)= & \frac{\pi-2+\sqrt{2}}{\pi(\pi-2)} .
\end{aligned}
$$

It is easy to check that assumptions $\left(S_{1}\right)-\left(S_{3}\right)$ hold. Set $a=12$, $a_{1}=10$. Then we can verify that conditions $\left(\mathrm{H}_{1}\right)$ and $\left(\mathrm{H}_{2}\right)$ and (33) are satisfied. Then applying Theorem 4, BVP (50) has two concave symmetric positive solutions $w^{*}, v^{*} \in P$ with

$$
\begin{gathered}
\left\|w^{*}\right\|_{\infty} \leqslant 10, \\
\lim _{n \rightarrow \infty} T^{n} w_{0}=w^{*},
\end{gathered}
$$

where

$$
\begin{gathered}
w_{0}(t)=\frac{60 t(1-t)+10}{3 \pi(\pi-2)} . \\
\left\|v^{*}\right\|_{\infty} \leqslant 10, \\
\lim _{n \rightarrow \infty} T^{n} v_{0}=v^{*},
\end{gathered}
$$

where

$$
v_{0}(t)=0
$$

\section{Conflict of Interests}

The authors declare that there is no conflict of interests regarding the publication of this paper.

\section{Acknowledgments}

This research is supported by the Beijing Higher Education Young Elite Teacher Project (Project no. YETP0322) and Chinese Universities Scientific Fund (Project no. 2013QJ004).

\section{References}

[1] B. Liu, "Positive solutions of fourth-order two point boundary value problems," Applied Mathematics and Computation, vol. 148, no. 2, pp. 407-420, 2004

[2] Y. Li, "Positive solutions of fourth-order boundary value problems with two parameters," Journal of Mathematical Analysis and Applications, vol. 281, no. 2, pp. 477-484, 2003.

[3] X. Liu and W. Li, "Existence and multiplicity of solutions for fourth-order boundary value problems with three parameters," Mathematical and Computer Modelling, vol. 46, no. 3-4, pp. 525534, 2007.

[4] Z. Bai, "The upper and lower solution method for some fourthorder boundary value problems," Nonlinear Analysis: Theory, Methods \& Applications, vol. 67, no. 6, pp. 1704-1709, 2007.
[5] G. Chai, "Existence of positive solutions for fourth-order boundary value problem with variable parameters," Nonlinear Analysis: Theory, Methods \& Applications, vol. 66, no. 4, pp. 870880, 2007.

[6] M. Pei and S. K. Chang, "Monotone iterative technique and symmetric positive solutions for a fourth-order boundary value problem," Mathematical and Computer Modelling, vol. 51, no. 910 , pp. 1260-1267, 2010.

[7] J. R. Cannon, "The solution of the heat equation subject to the specification of energy," Quarterly of Applied Mathematics, vol. 21, no. 2, pp. 155-160, 1963.

[8] N. I. Ionkin, "The solution of a certain boundary value problem of the theory of heat conduction with a nonclassical boundary condition," Differentsial Equations, vol. 13, no. 2, pp. 294-304, 1977.

[9] R. Y. Chegis, "Numerical solution of a heat conduction problem with an integral boundary condition," Litovskii Matematicheskii Sbornik, vol. 24, pp. 209-215, 1984.

[10] A. Boucherif, "Second-order boundary value problems with integral boundary conditions," Nonlinear Analysis A: Theory, Methods and Applications, vol. 70, no. 1, pp. 364-371, 2009.

[11] M. Feng, "Existence of symmetric positive solutions for a boundary value problem with integral boundary conditions," Applied Mathematics Letters: An International Journal of Rapid Publication, vol. 24, no. 8, pp. 1419-1427, 2011.

[12] Y. Wang, G. Liu, and Y. Hu, "Existence and uniqueness of solutions for a second order differential equation with integral boundary conditions," Applied Mathematics and Computation, vol. 216, no. 9, pp. 2718-2727, 2010.

[13] H. Ma, "Symmetric positive solutions for nonlocal boundary value problems of fourth order," Nonlinear Analysis: Theory, Methods \& Applications, vol. 68, no. 3, pp. 645-651, 2008.

[14] X. Zhang, M. Feng, and W. Ge, "Symmetric positive solutions for $p$-Laplacian fourth-order differential equations with integral boundary conditions," Journal of Computational and Applied Mathematics, vol. 222, no. 2, pp. 561-573, 2008.

[15] Z. Bai, "Positive solutions of some nonlocal fourth h-order boundary value problem," Applied Mathematics and Computation, vol. 215, no. 12, pp. 4191-4197, 2010. 


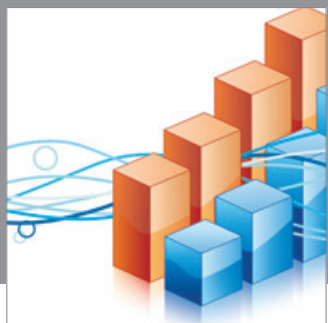

Advances in

Operations Research

mansans

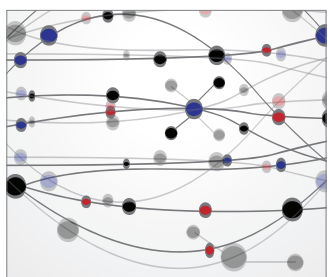

The Scientific World Journal
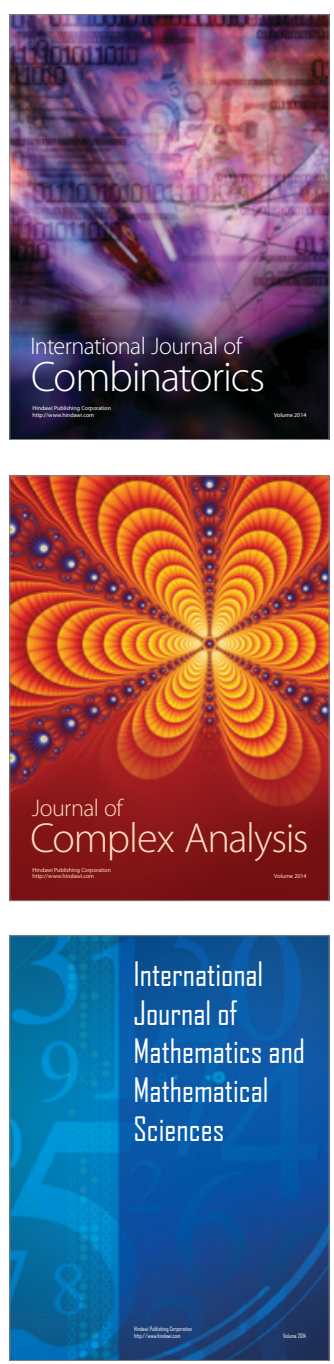
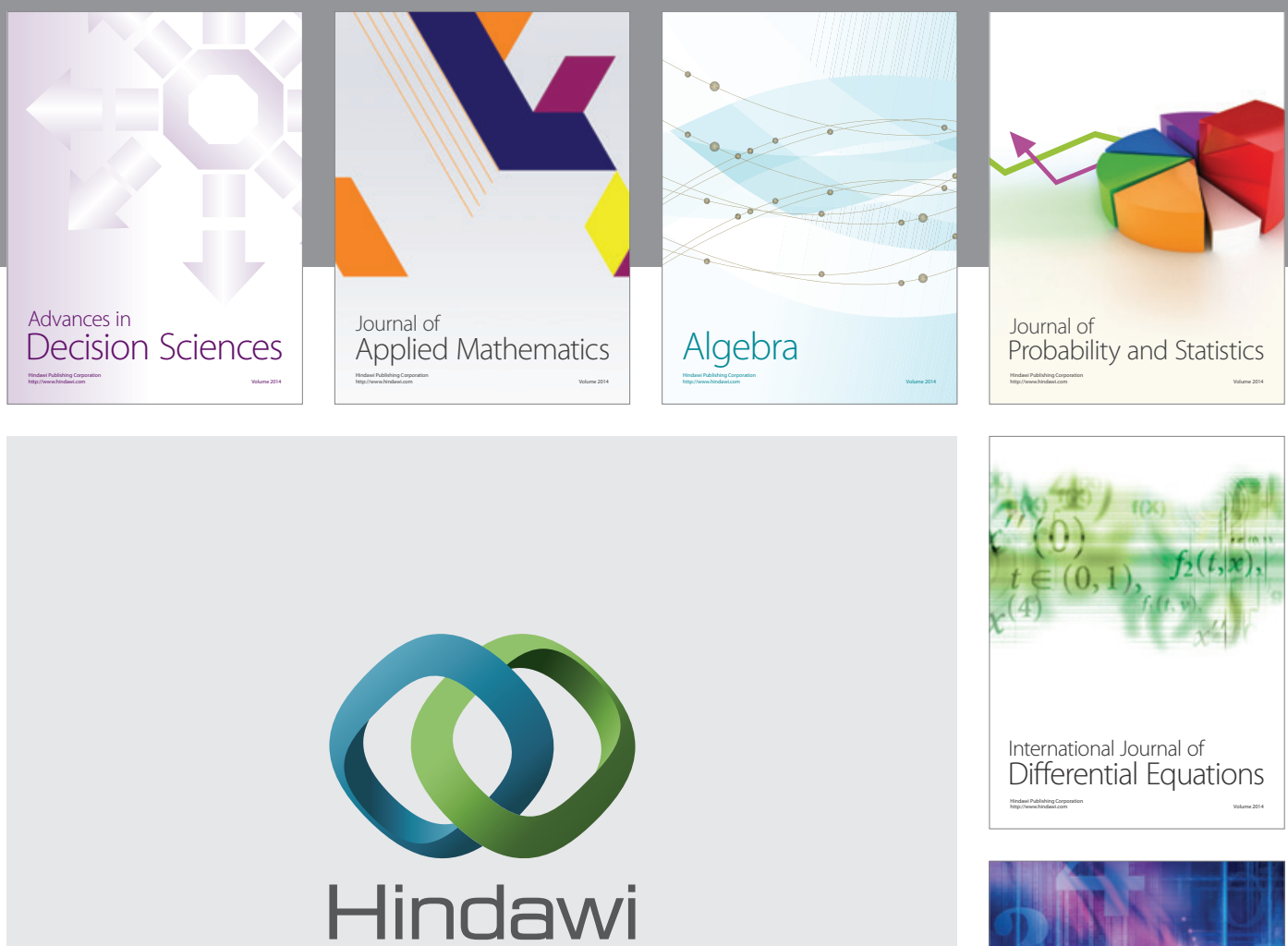

Submit your manuscripts at http://www.hindawi.com
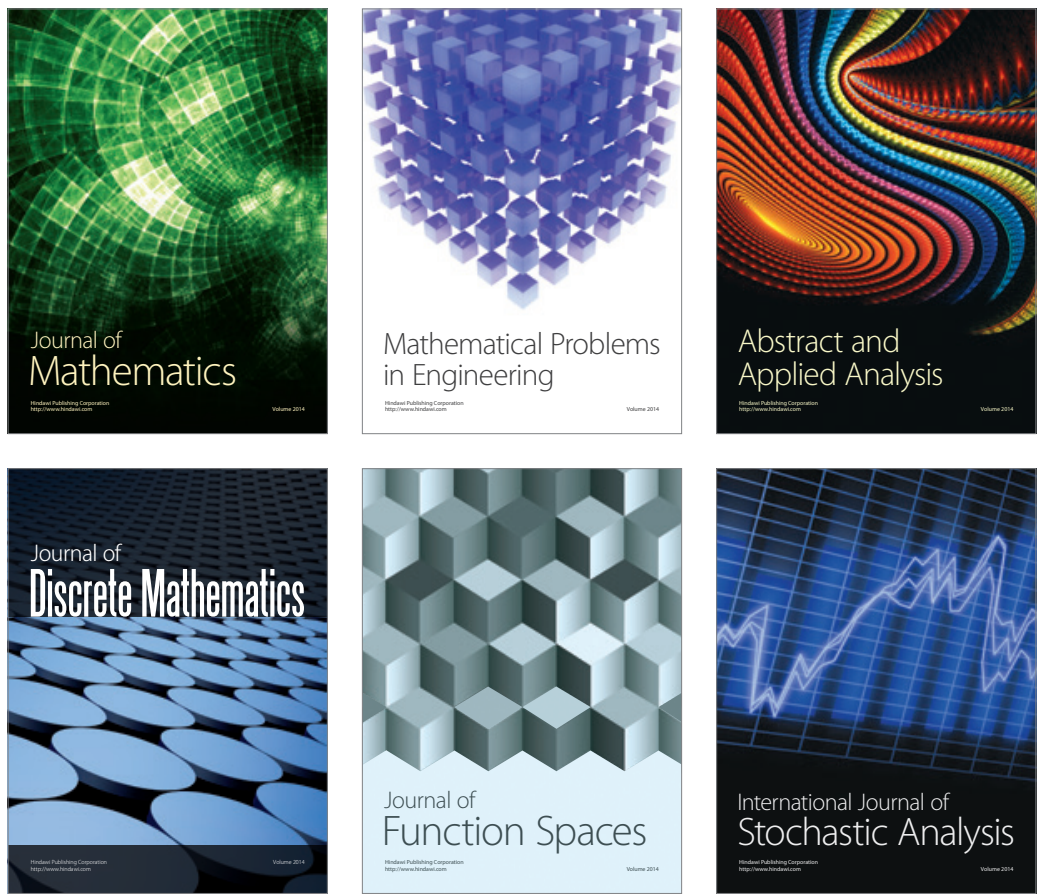

Journal of

Function Spaces

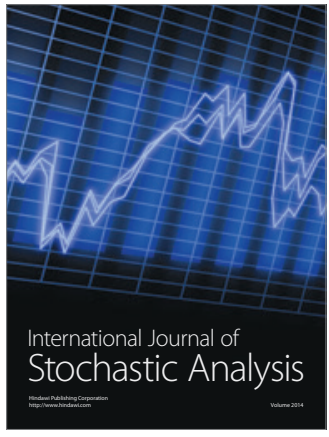

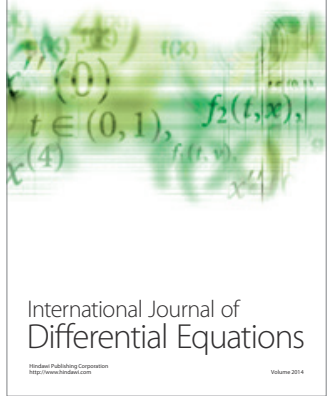
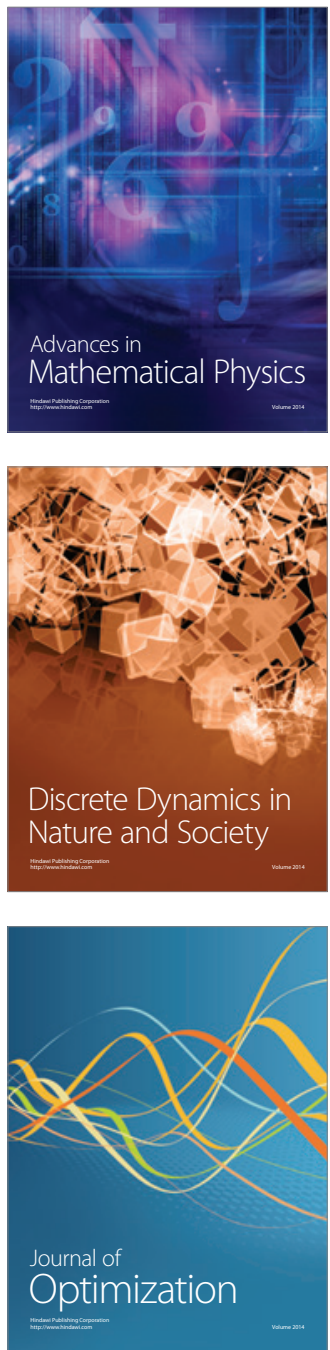